\title{
RATING PROCEDURE FOR MIXED AIR-SOURCE UNITARY HEAT PUMPS OPERATING IN THE HEATING MODE
}

\section{Piotr A. Domanski}

\author{
U.S. DEPARTMENT OF COMMERCE \\ Natlonal Institute of Standards \\ and Tochnology \\ Calthorsburg, MD 20899
}

U.S. Department of Enorsy Office of Bulding and Community systems Conservation and Renowable Energy Washington, DC 20585
U.S. DEPARTMENT OF COMMERCE Robert A. Mobbacher, Socretary NATIONAL INSTIUTTE OF STANDARDS AND TECHNOLOQY

Dr. John W. Lyons, Director 



\section{RATING PROCEDURE FOR MIXED AIR-SOURCE UNITARY HEAT PUMPS OPERATING IN THE HEATING MODE}

Piotr A. Domanski

U.S. DEPARTMENT OF COMMERCE Natlonal instltute of Standards and Tochnology

Galthersburk, MD 20899

U.S. Department of Energy Orfece of Bullding and Community Systems Conservation and Renewable Energy Washington, DC 20585

May 1990

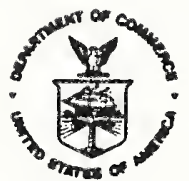

U.S. DEPARTMENT OF COMMERCE Robort A. Mosbacher, Secretary NATONAL INSTITUTE OF STANDARDS AND TECHNOLOOY

Dr. John W. Lyone, Dlrector 



\section{Abstract}

A procedure is presented for determining the heating performance ratings of air-source unitary heat pumps consisting of an outdoor section and an indoor section which were not tested together as a system. The procedure allows calculation of capacity at the $47^{\circ} \mathrm{F}$ rating point and heating seasonal performance factor, HSPF, using as a reference point performance ratings of the outdoor unit tested under current DoE procedures in conjunction with a different indoor section. This procedure requires as input data the matched system rated performance, the ratio of condensing capacities of mixed and matched indoor coils, and the ratio of powers of mixed and matched indoor fans.

Key Words: capacity, heat pump, mixed system, mixed-matched system, rating procedure, seasonal efficiency 

1. PURPOSE . . . . . . . . . . . . . . . . . . . . . . . . . . 1

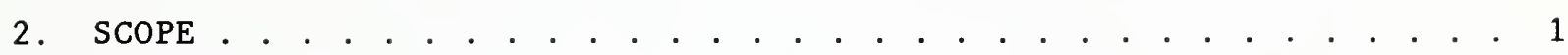

3. DEFINITIONS . . . . . . . . . . . . . . . . . . . . . . . . . . . . . . . 1

4. PROCEDURE FOR RATING A MIXED SYSTEM . . . . . . . . . . . . . . . . . . 2

4.1 Rating Correlations. . . . . . . . . . . . . . . 2

4.2 Determination of the Heating Capacity of Indoor Coils..... . 3

4.2.1 Definitions. . . . . . . . . . . . . . . . . . . 3

4.2.2 Restrictions..................... . . . 4

4.2.3 Verification of Coil Capacity Determination Method... . 4

4.3 Expansion Device Scaling Factor. . . . . . . . . . . . . . . 5

4.3.1 Determination of the Cooling Mode Expansion Device Scaling Factor...... . . . . . . . . . . . . 5

4.3.2 Restrictions . . . . . . . . . . . . . . . . . . . 6

4.3.3 Equations for Calculating the Expansion Device Scaling Factor....................... . 7

4.4 Power Input to the Indoor Fan. . . . . . . . . . . . . . . . . . 7

4.4.1 Power Input to the Indoor Fan of the Matched System. . . . 7

4.4.2 Power Input to the Indoor Fan of the Mixed System. . . . . 8

4.5 Values of Ratings. . . . . . . . . . . . . . . . . . . . . . 8

4.5.1 Values of Capacity at the $47^{\circ} \mathrm{F}$ Temperature Test. . . . . . 8

4.5.2 Values of the Heating Seasonal Performance Factor. . . . . 8

5. ALTERNATIVE RATING PROCEDURES FOR MIXED SYSTEMS . . . . . . . . . . . 8

6. REFERENCES. . . . . . . . . . . . . . . . . . . . . . . . . . . 9 



\section{PURPOSE}

The purpose of this report is to establish procedures for determining the heating performance ratings of air-source unitary heat pumps consisting of an outdoor unit and an indoor section which were not tested together as a system. The performance ratings covered in this document are the heating capacity at the High Temperature Test at $47^{\circ} \mathrm{F}$ and Heating Seasonal Performance Factor, HSPF, for Region IV at the minimum design heating requirement, as defined by the DoE Test Procedures contained in Appendix $M$ to Subpart B of the Code of Federal Regulations [1]. This rating methodology is a composite of independent measurements and calculations made on an outdoor unit in conjunction with a matched indoor coil, and a mixed indoor coil. It supplements and is similar in format to the rating procedure for mixed systems operating in the cooling mode [2].

\section{SCOPE}

This procedure applies to residential heat pump systems charged with Refrigerant 22 , whose matched system* cooling capacity ${ }^{*}$ is less than $65,000 \mathrm{Btu} / \mathrm{h}$ $(19,050 \mathrm{~W})$. The covered systems consist of an indoor air-heating coil assembly, and an outdoor air-source coil assembly equipped with an electric, single-phase, single-speed, reciprocating compressor. This procedure does not apply to systems in which compressor control strategy changes with load (e.g., cylinder unloading, hot-gas bypass, systems employing multi-speed compressors or more than one compressor). Additional limitations as to the quantitative range of the scope of this document are given in Section 4.2.2 and 4.3.2.

\section{DEFINITIONS}

All definitions included in or cited by Title 10, Part 430 of the Code of Federal Regulations [1] shall be considered part of this procedure in addition to the following definitions.

3.1 ARI - Air Conditioning and Refrigeration Institute.

3.2 Air Source Unitary Heat Pump or Unitary System - an outdoor unit combined with an indoor coil assembly.

3.3 Outdoor Unit - an assembly of refrigerating components designed to compress and liquify (cooling mode), and evaporate and compress (heating mode) a specific refrigerant. It consists of a refrigerant vapor compressor air-to-refrigerant coil, coil fan and motor, and regularly furnished accessories. A liquid line solenoid valve and other cyclic performanceenhancing devices (including the heating mode expansion device), if included in a heat pump, are considered to be a part of the outdoor unit.

3.4 Indoor Coil Assembly - an assembly consisting of a coil, condensate collecting pan, and expansion device, and which may or may not include a blower, motor and cabinet.

\footnotetext{
* Refer to Section 3, Definitions.

* As defined by DoE Test Procedures, Appendix M to Subpart B of [1].
} 
3.5 Matched Coil - an indoor coil which is a part of the matched system.

3.6 Matched System - a unitary system which has been tested and rated in accordance with Appendix M to Subpart B of Title 10, Part 430 of the Code of Federal Regulations [1].

3.7 Mixed Coil - an indoor coil which is used in a unitary system instead of the matched coil.

3.8 Mixed System - a unitary system which is not a matched system.

3.9 Shall - where 'shall' or 'shall not' are used for a provision specified, that provision is mandatory if compliance with the procedure is claimed.

3.10 Should, Recommended, or It Is Recommended - 'should', 'recommended', or 'it is recommended' are used to indicate provisions which are not mandatory but which are desirable as good practice.

\section{PROCEDURE FOR RATING MIXED SYSTEM}

\subsection{Rating Correlations}

Mixed system capacity at the $47^{\circ} \mathrm{F}$ temperature test [1], $Q_{x}(47)$, shall be calculated using equation 4.1. Mixed system Heating Seasonal Performance Factor, $\mathrm{HSPF}_{\mathrm{x}}$, shall be calculated using equation 4.2 or equation 4.3 depending on the type of heating mode expansion device.

Capacity at the $47^{\circ} \mathrm{F}$ test, $\mathrm{Q}_{\mathrm{x}}(47)$

$$
\mathrm{Q}_{\mathrm{x}}(47)=\left[\mathrm{Q}_{\mathrm{m}}(47)-3.413 \cdot \mathrm{P}_{\mathrm{f}, \mathrm{m}}\right]\left[\frac{\mathrm{Q}_{\mathrm{c}, \mathrm{x}}}{\mathrm{Q}_{\mathrm{c}, \mathrm{m}}}\right]^{0.22}+3.413 \cdot \mathrm{P}_{\mathrm{f}, \mathrm{x}}
$$

Heating Seasonal Performance Factor, $\mathrm{HSPF}_{\mathrm{x} \text { - }}$

Equations 4.2 shall be used for systems employing a capillary tube (capillary tubes) or a short tube (short tubes) as the heating mode expansion device.

$$
\mathrm{HSPF}_{\mathrm{x}}=\mathrm{HSPF}_{\mathrm{m}} \frac{1.428 \frac{\mathrm{Q}_{\mathrm{x}}(47)}{\mathrm{Q}_{\mathrm{m}}(47)}}{\left[\frac{\mathrm{Q}_{\mathrm{x}}(47)}{\mathrm{Q}_{\mathrm{m}}(47)}\right]^{-0.31}+0.141\left[\frac{\mathrm{P}_{\mathrm{f}, \mathrm{x}}}{\mathrm{P}_{\mathrm{f}, \mathrm{m}}}+1\right]+0.146 \frac{\mathrm{Q}_{\mathrm{x}}(47)}{\mathrm{Q}_{\mathrm{m}}(47)}}
$$


Equation 4.3 shall be used for systems employing a thermostatic expansion valve or an electronic expansion valve as the heating mode expansion device.

$$
\mathrm{HSPF}_{\mathrm{x}}=\mathrm{HSPF}_{\mathrm{m}} \frac{1.428 \frac{\mathrm{Q}_{\mathrm{x}}(47)}{\mathrm{Q}_{\mathrm{m}}(47)}}{\left[\frac{\mathrm{Q}_{\mathrm{x}}(47)}{\mathrm{Q}_{\mathrm{m}}(47)}\right]^{-0.46}+0.141\left[\frac{\mathrm{P}_{\mathrm{f}, \mathrm{x}}}{\mathrm{P}_{\mathrm{f}, \mathrm{m}}}+1\right]+0.146}
$$

where

$$
\begin{aligned}
& \mathrm{HSPF}_{\mathrm{m}}=\text { Heating Seasonal Performance Factor of the matched system } \\
& \text { as certified by its manufacturer for the minimum design } \\
& \text { heating requirement in Region IV (Btu/(h.watt)) } \\
& \mathrm{HSPF}_{\mathrm{x}}=\text { Heating Seasonal Performance Factor of the mixed system } \\
& \text { as calculated by equation } 4.2 \text { or } 4.3 \text { (Btu/(h・watt)) } \\
& \mathrm{P}_{\mathrm{f}, \mathrm{m}}=\text { indoor fan power of a matched system as defined in section 4.4.1 } \\
& \mathrm{P}_{\mathrm{f}, \mathrm{x}}=\text { indoor fan power of the mixed system as defined in section 4.4.2 } \\
& \mathrm{Q}_{c, m}=\text { heating capacity of the matched coil as defined in section } 4.2 \\
& \mathrm{Q}_{c}, \mathrm{x}=\text { heating capacity of the mixed coil as defined in section } 4.2 \\
& \mathrm{Q}_{m}(47)=\text { heating capacity of the matched system at the } 47^{\circ} \mathrm{F} \text { temperature } \\
& \text { test as certified by its manufacturer for the minimum } \\
& \text { design heating requirement in Region IV (Btu/h) } \\
& \mathrm{Q}_{\mathbf{x}}(47)=\text { capacity of } \mathrm{a} \text { mixed system at the } 47^{\circ} \mathrm{F} \text { temperature test as } \\
& \text { calculated by equation } 4.1 \quad(B t u / h)
\end{aligned}
$$

\subsection{Determination of Heating Capacity of the Indoor Coils}

\subsubsection{Definitions}

$Q_{c, m}=$ heating, dry surface capacity of the matched coil (Btu/h) at the indoor air volumetric flow rate, CFM $\left(\mathrm{ft}^{3} / \mathrm{min}\right)$, at which matched system capacity, $Q_{m}(47)$, was measured. If $C F M_{m}$ information is not available, the value for the indoor air volumetric flow rate shall be calculated as follows:

$$
\mathrm{CFM}_{\mathrm{m}}=\frac{\mathrm{Q}_{\mathrm{m}}(95)}{12000} \cdot 425\left(\mathrm{ft}^{3} / \mathrm{min}\right)
$$

where $Q_{m}$ (95) is the capacity of the matched system at Test $A$ [1] as certified by its manufacturer $(B t u / h)$.

$Q_{c, x}=$ heating, dry surface capacity of the mixed coil (Btu/h) at the indoor air volumetric flow rate, $\mathrm{CFM}_{x}\left(\mathrm{ft}^{3} / \mathrm{min}\right)$, specified for the mixed system. The air volumetric flow rate specified for the mixed system shall satisfy conditions of Appendix M to Subpart B of [1].

Heating capacities of the matched and mixed coil shall be obtained using the same verified method (see Section 4.2.3). The capacities should be obtained 
at the following conditions:

- inlet air temperature - $70^{\circ} \mathrm{F}$ dry bulb

- refrigerant saturation temperature at the coil inlet - $110^{\circ} \mathrm{F}$

- identical refrigerant subcooling at the coil outlet

If coil capacities are obtained by means of a catalog or computer simulation, the same catalog or computer simulation shall be used for both coils. Coil material and geometry (e.g., inside tube diameter, tube staggering, fin spacing, fin thickness, fin shape, and number of tube rows) shall be accounted for by the method used. That is, the methodology must use these parameters as independent variables.

\subsubsection{Restrictions}

The internal volume of the mixed indoor coil assembly

a) shall not be smaller than the volume of the smallest indoor coil assembly certified with a given outdoor unit by the outdoor unit manufacturer,

b) shall not exceed the internal volume of the matched coil assembly by more than 20 percent, or shall not exceed the volume of the largest coil certified with a given outdoor unit by the outdoor unit manufacturer, whichever is larger.

The heating capacity of the mixed coil

a) shall not be less than the capacity of the lowest capacity indoor coil certified with a given outdoor unit by the outdoor unit manufacturer, and shall not be less than 85 percent of the matched indoor coil.

b) shall not exceed the capacity of the matched coil by more than 20 percent, or shall not exceed the capacity of the highest capacity coil certified with a given outdoor unit by the outdoor unit manufacturer, whichever is larger. In the later case, the values 1.2 for $Q_{c, x} / Q_{c}, m$ shall be used.

The internal surface of the tubes of the mixed coil shall be smooth unless the matched indoor coil tubes have an enhanced heat transfer surface. In this case the mixed indoor coil shall either employ tubes of the same diameter and inside surface design, or shall have smooth surface tubes.

\subsubsection{Verification of Coil Capacity Determination Method}

A variety of methodologies exist for calculating the capacity of a coil based on material and geometry data only. For example, several large heat exchanger manufacturing companies publish catalogues of performance curves for their specific products which are commonly used in a generic fashion. That is, the capacity of coils of the same materials and of the same number of rows, tube 
patterns and diameters, fin spacing, shape, and thickness is assumed to be the same for all manufacturers. Similarly, there exist many computer simulations which are based either on regression analysis of the above mentioned catalogue data or on first principles of the heat transfer phenomena involved. If a specific methodology of either of these categories has at least the independent variables listed above, it may be used in this procedure to predict the capacities of the coils (i.e., $Q_{c, x}$ and $Q_{c, m}$ ). However, the specific methodology chosen must be verified by test, in accordance with ASHRAE Standard 33-88 [3] and ARI Standard 410-81 [4], to demonstrate that it is sufficiently accurate to simulate the coil line which is being used in the mixed system rating.

This verification requires that, for a given coil line, the capacity range over which the methodology is used to predict capacity values must be straddled by at least two tests which are within 58 agreement with the predicted values. For example, if a manufacturer produces a line of coils with six sizes having capacities ranging from $20000 \mathrm{Btu} / \mathrm{h}$ to $33000 \mathrm{Btu} / \mathrm{h}$ and uses other than test methodology (e.g., computer simulation) to predict the six individual capacity values, the methodology must be within 5 o agreement with the test values of the smallest $(20000 \mathrm{Btu} / \mathrm{h})$ and the largest $(33000 \mathrm{Btu} / \mathrm{h})$ coil. A similar pair of tests straddling the matched coil is also required if the methodology has not been previously verified for that line.

A coil line is defined as a group of coils which are of the same materials and bonding procedure, configuration (i.e., flat or A-shape), row staggering, fin thickness, fin spacing, fin shape (i.e., flat, corrugated edge, same wave or lance design, etc.), tube diameters and internal surface design. If any of these parameters differ, then a new coil line has been defined and a new verification test pair is required for the methodology.

It is recognized that different numbers of tube rows and circuitry are not being considered as defining a new coil line, yet they probably have a significant effect on performance, all other parameters being held constant. However, the state of the art of coil performance simulation or representation is such that these variables are seldom considered. Some first principle computer simulation programs, such as the one used to develop this standard [5], do exist but they are not widely available and are usually so complex that input errors are easily possible. Therefore, it appears unreasonable to require this degree of sophistication for coil rating at this time.

\subsection{Expansion Device Scaling Factor}

\subsubsection{Determination of the Cooling Mode Expansion Device Scaling Factor}

This rating methodology requires that the heating mode expansion device is the same in the matched and mixed systems. However, restriction of the cooling mode expansion device is allowed to be different to some degree. The cooling mode expansion device scaling factor, $F_{\theta}$, provides a measure of the relative restrictiveness of the matched and mixed cooling mode expansion devices. Although the expansion device scaling factor does not appear in the rating algorithms, its value shall be determined to verify that this rating methodology can be applied to the considered mixed system. 
The expansion device scaling factor, $F_{e}$, depends on the type of matched and mixed expansion devices involved. It shall be determined using Table 1 , which provides a value for the scaling factor or refers to the equation by which the scaling factor shall be calculated.

Table 1. Evaluation of the Cooling Mode Expansion Device Scaling Factor

\begin{tabular}{|c|c|c|}
\hline \multicolumn{2}{|c|}{ Expansion Device } & \multirow{2}{*}{$\mathrm{F}_{\mathrm{e}}$} \\
\hline Matched System & Mixed System & \\
\hline TXV, no bleed or bleed & $\mathrm{TXV}$, no bleed or bleed ${ }^{*}$ & 1.0 \\
\hline $\begin{array}{l}\text { Capillary } \\
\text { or } \\
\text { Short Tube Restrictor }\end{array}$ & $\mathrm{TXV}$, no bleed or bleed $\mathrm{d}^{\star *}$ & 1.0 \\
\hline Capillary & Capillary & eq. 4.5 \\
\hline Capillary & Short Tube Restrictor & eq. 4.5 \\
\hline Short Tube Restrictor & Capillary & eq. 4.5 \\
\hline Short Tube Restrictor & Short Tube Restrictor & eq. 4.5 \\
\hline
\end{tabular}

" the mixed TXV shall have equivalent capacity and same superheat setting as the matched TXV

${ }^{\star *}$ the mixed TXV shall have equivalent capacity as the matched expansion device

\subsubsection{Restrictions}

This rating procedure shall not be used for any system if:

a) the expansion device scaling factor, $F_{\theta}$, is outside the range $0.95-1.15$

b) the mixed system has a combination of capillary tubes or short tube restrictors connected in series,

c) the matched system has a combination of capillary tubes or short tube restrictors connected in series,

d) the matched system has a TXV and the mixed system has either a capillary tube or a short tube restrictor, unless the outdoor section manufacturer also certifies a system in which a TXV is replaced by a capillary tube or short tube restrictor type expansion device. In such a case, this system may be considered as a matched system and its performance data may be used for calculation of performance of the mixed system. 
The expansion device scaling factor, $F_{e}$, is the ratio of summations of refrigerant mass flow rates through the mixed $\left(m_{x, i}\right)$ and matched $\left(m_{m, j}\right)$ expansion devices, connected in parallel, at the same operating conditions.

$$
F_{e}=\frac{\sum m_{x}}{\sum m_{m}}=\frac{m_{x, 1}+m_{x, 2}+\ldots \cdot m_{x, 1}}{m_{m, 1}+m_{m, 2}+\cdot \cdot \cdot m_{m, j}}
$$

Subscripts $\mathrm{x}$ and $\mathrm{m}$ refer to mixed and matched expansion devices, and subscripts $i$ and $j$ correspond to the number of parallel connected capillary tubes or short tube restrictors in the mixed and matched expansion devices, respectively. The operating conditions selected for calculation of the expansion device scaling factor are: pressure of 250 psia and $13^{\circ} \mathrm{F}$ subcooling at inlet, and the saturation temperature of $45^{\circ}$ in the evaporator.

Evaluation of the mass flow rate, $m$, depends on the type of flow restrictor. For a capillary tube the following equation shall be used:

$$
\mathrm{m}=109.6 \cdot \Phi
$$

where $\Phi$ is the flow factor for the capillary tube employed, determined from its geometry with the aid of the ASHRAE Handbook, Equipment Volume, 1988, Chapter 19, Figure 39 [6].

Refrigerant mass flow rate through a short tube restrictor shall be calculated by the following equations [7]:

$$
\begin{aligned}
& \mathrm{m}=15955 \cdot \mathrm{C}_{\mathrm{c}} \cdot \mathrm{D}^{2} \cdot\left(250-\mathrm{P}_{2}\right)^{0.5}(\mathrm{lb} / \mathrm{h}) \\
& \mathrm{C}_{\mathrm{c}}=1+0.104 \cdot \mathrm{DEPTH}^{0.64} \cdot(\mathrm{L} / \mathrm{D})^{0.27} \\
& \mathrm{P}_{2}=209.92\left[1.061-0.123 \cdot \mathrm{e}^{-0.017 \cdot(\mathrm{L} / \mathrm{D})^{2}}\right]
\end{aligned}
$$

where: $D$ (inch) denotes the inner diameter and $L$ (inch) denotes the length of the short tube restrictor. Symbol DEPTH (inch) denotes the depth of the inlet

chamfer. The length dimensions required in the prescribed equation shall be measured by methods providing accuracy of $\pm 1.5 \%$.

\subsection{Power Input to the Indoor Fan}

\subsubsection{Power Input to the Indoor Fan of the Matched System}

Power input to the indoor fan, $P_{f, m}$, shall be measured in accordance with Appendix $M$ to Subpart $B$ of [1], at the indoor-air volumetric flow rate, $\mathrm{CFM}_{\mathrm{m}}$, at which capacity of the matched system, $Q_{m}(47)$, was measured. If $C M_{m}$ information is not available, the value for the indoor air volumetric flow rate shall be calculated by equation 4.4. If the indoor fan is not supplied with the system, $P_{f, m}$ shall be evaluated by the equation: 


$$
P_{f, m}=0.365 \cdot \mathrm{CFM}_{m}
$$

where $\mathrm{CFM}_{\mathrm{m}}\left(\mathrm{ft}^{3} / \mathrm{min}\right)$ is a volumetric flow of air through the matched indoor coil at which system capacity, $\mathrm{Q}_{\mathrm{m}}(47)$, was measured.

\subsubsection{Power Input to the Indoor Fan of the Mixed System}

Power input to the indoor $f a n, P_{f, x}$, shall be measured in accordance with Appendix $M$ to Subpart B of [1], at the indoor-air volumetric flow rate, $\mathrm{CFM}_{x}$, at which capacity of the mixed system, $Q_{\mathbf{x}}(47)$, is evaluated. If the indoor fan is not supplied with the system, $P_{f, x}$ shall be evaluated by the equation:

$$
P_{f, x}=0.365 \cdot \mathrm{CFM}_{x}
$$

where $\mathrm{CFM}_{\mathrm{x}}\left(\mathrm{ft}^{3} / \mathrm{min}\right)$ is the volumetric flow of air through the mixed indoor coil at which the capacity of the mixed system, $Q_{x}(47)$, is to be evaluated.

\subsection{Values of Ratings}

\subsubsection{Values of Capacity at the $47^{\circ} \mathrm{F}$ Temperature Test}

The capacity at the $47^{\circ} \mathrm{F}$ temperature test, $\mathrm{Q}(47)$, shall be expressed in $B t u / h$

(W) in multiples of:

$\begin{array}{ll}\frac{\text { Capacities }}{\text { Btu/h (W) }} & \frac{\text { Multiples }}{\text { Btu/h (W) }} \\ \text { Less than 20,000 (less than 5,900) } & 100(30) \\ 20,000 \text { up to } 38,000 \text { (5,900 up to } 11,000) & 200(60) \\ \text { Greater than } 38,000 \text { (greater than } 11,100) & 500(150)\end{array}$

The reported capacity value, $Q(47)$, shall not exceed the $Q_{x}(47)$ value as calculate by equation $(4.1)$.

\subsubsection{Values of the Heating Seasonal Performance Factor}

The Heating Seasonal Performance Factor, HSPF, shall be expressed in multiples of 0.05 . The value of the Heating Seasonal Performance Factor shall not exceed the $\mathrm{HSPF}_{\mathrm{x}}$ value as calculated by the rating algorithm (equation 4.2 or 4.3 ).

\section{ALTERNATIVE RATING PROCEDURE FOR MIXED SYSTEMS}

The large number of variables and the complexities of their interactions associated with a heat pump always make theoretical or quasi-empirical rating procedures less certain than a whole system test. Therefore, an acceptable alternative to this entire methodology is a formal certification program in which performance of a significant number of the mixed systems created by the use of a single coil line is measured. 
This rating procedure was developed based on characteristics of equipment which was considered to be a "typical" system. Other rating procedures that may produce ratings of comparable or better accuracy would probably be those which were developed for specific production lines and/or utilize more input data on the matched and mixed components, if such data are available. Also some alteration of this rating procedure may be warranted if supported by test data of a given component (e.g. application of a test data based correlation for an expansion device of a specific design).

\section{REFERENCES}

1. Code of Federal Regulations, Title 10, Part 430, Washington, D.C., 1985.

2. Domanski, P.A., Rating Procedure for Mixed Air-Source Unitary Air Conditioners and Heat Pumps Operating in the Cooling Mode - Revision 1, NISTIR 89-4071, National Institute of Standards and Technology, Gaithersburg, MD , 1989 .

3. American Society of Heating, Refrigerating, and Air-Conditioning Engineers, Inc., Standard 33-88, Method of Testing Forced Circulation Air-Cooling and Air-Heating Coils, New York, NY, 1988.

4. Air-Conditioning and Refrigeration Institute, Standard 410-81, Standard for Forced-Circulation Air-Cooling and Air-Heating Coils, Arlington, VA, 1981.

5. Domanski, P.A. and Didion, D.A., Computer Modeling of the Vapor Compression Cycle With Constant Flow Area Expansion Device, NBS Building Science Series 155, National Bureau of Standards, Gaithersburg, MD, 1983 .

6. American Society of Heating, Refrigeration, and Air-Conditioning Engineers, Inc., ASHRAE Handbook, Equipment Volume, Chapter 19, Fig. 39, Atlanta, GA, 1988.

7. Aaron, D.A. and Domanski P.A., An Experimental Investigation and Modeling of the Flow Rate of Refrigerant 22 through the Short Tube Restrictor, NISTIR 89-4120, National Institute of Standards and Technology, Gaithersburg, MD, 1989. 



\section{BIBLIOGRAPHIC DATA SHEET}

1. PUBUCATION OA AEPORT NUMBEA NISTIR 90-4298

2. PERFORMING ORGANIZATION REPORT NUMBER

3. PUBUCATION DATE

MAY 1990

4. TITLE AND SUBTITLE

Rating Procedure for Mixed Air-Source Unitary Heat Pumps Operating in the Heating Mode

5. AUTHOR(S)

Piotr A. Domanski

6. PERFORMINO ORQANIZATION (IF JOINT OR OTHER THAN NIST, SEE INSTRUCTIONS) U.S. DEPARTMENT OF COMMERCE NATIONAL INSTITUTE OF STANDARDS AND TECHNOLOGY GAITHERSBURG, MD 20899

7. CONTRACT/ORANT NUMBER

8. TYPE OF REPORT AND PERIOD COVERED

9. SPONSORINQ ORGANIZATION NAME AND COMPLETE ADDRESS (STREET, CITY, STATE, ZIP)

U.S. Department of Energy

Office of Building and Community Systems

Conservation and Renewable Energy

Washington, DC 20585

10. SUPPLEMENTARY MOTES

DOCUMENT DESCRIBES A COMPUTER PROGRAM: SF-185, FIPS SOFTWARE SUMMAAY, IS ATTACHED.

11. ABSTRACT (A 200-WORD OA LESS FACTUAL SUMMAAY OF MOST SIQNIFICANT INFORMATION. IF DOCUMENT INCLUDES A SIQNIFICANT BIBUOQAAPHY OA UTERATURE SUAVEY, MENTION IT HERE.)

A procedure is presented for determining the heating performance ratings of air-source unitary heat pumps consisting of an outdoor section and an indoor section which were not tested together as a system. The procedure allows calculation of capacity at the $47^{\circ} \mathrm{F}$ rating point and heating seasonal performance factor, HSPF, using as a reference point performance rat-ings of the outdoor unit tested under current DOE procedures in conjunction with a different indoor section. This procedure requires as input data the matched system rated performance, the ratio of condensing capacities of mixed and matched indoor coils, and the ratio of powers of mixed and matched indoor fans.

12. KEY WOADS (6 TO 12 ENTRIES; ALPHABETICAL ORDEA; CAPITALIZE ONLY PROPER MAMES; AND SEPARATE KEY WORDS BY SEMICOLONS) capacity, heat pump, mixed system, mixed-matched system, rating procedure, seasonal efficiency

\section{AVAILABILTY}

UNUMTED

FOR OfFICIAL DISTAIBUTION. DO NOT RELEASE TO NATIONAL TECHNICAL INFORMATION SEAVICE (NTIS).

ORDER FROM SUPERINTENDENT OF DOCUMENTS, U.S. COVERNMENT PAINTING OFFICE, WASHINGTON, DC 20402.

ORDER FROM NATIONAL TECHNICAL INFORMATION SERVICE (NTIS), SPAINGFIELD, VA 22161.
14. NUMBER OF PAINTED PAGES

14

15. PAICE

$\mathrm{A} 02$

\section{ELECTRONIC FORM}




